\title{
A retrospective, pooled data analysis of the safety of pegaptanib sodium in the treatment of age-related macular degeneration in subjects with or without diabetes mellitus
}

\author{
Theresa Dombi ${ }^{1 *}$, Kenneth K Kwok ${ }^{2}$ and Marla B Sultan ${ }^{2,3}$
}

\begin{abstract}
Background: To evaluate the safety of pegaptanib sodium $0.3 \mathrm{mg}$ intravitreal injection in the treatment of neovascular age-related macular degeneration in subjects with or without diabetes mellitus.

Methods: A pooled, retrospective, analysis was conducted of data from 9 sponsor-administered, randomized, openlabel trials. Subjects who received pegaptanib by randomization or change in dose assignment, crossover design, or protocol amendment, were included. Reports of endophthalmitis, increased intraocular pressure, retinal injury, intraocular hemorrhage, traumatic cataract, hypersensitivity reactions, stroke, myocardial infarction, and other arterial thromboembolic events defined by the Antiplatelet Trialists' Collaboration were identified by Medical Dictionary for Regulatory Activities preferred terms. Adverse events were summarized from the first injection to 42 days after the last injection. The incidence of adverse events was stratified by the presence/absence of diabetes.
\end{abstract}

Results: Of 1,586 subjects enrolled, 165 (10.4\%) had a history of diabetes mellitus and 1,421 (89.6\%) did not. The 2 populations were similar at baseline. Based on the comparison of prespecified ocular, hypersensitivity, and Antiplatelet Trialists' Collaboration event terms, the safety review did not identify any notable differences between the 2 populations.

Conclusions: This retrospective analysis found no increased safety risk resulting from treatment with pegaptanib $0.3 \mathrm{mg}$ in individuals with neovascular age-related macular degeneration and concomitant diabetes mellitus.

\section{Background}

Inflammation is thought to play an important role in the pathophysiology of diabetic retinopathy (DR) [1-3] with elevated levels of vascular endothelial growth factor (VEGF) being a key mediator [4]. The off-label intravitreal use of VEGF antagonists (with the exception of ranibizumab, which is currently approved in Europe) in the treatment of DR and diabetic macular edema (DME) appears to result in vision gains and reductions in central macular thickness [5,6]. Pegaptanib sodium is a selective VEGF antagonist first approved in the United States for the treatment of age-related macular degeneration (AMD) in December 2005. In retrospective studies

\footnotetext{
* Correspondence: Theresa.Dombi@Pfizer.com

${ }^{1}$ Pfizer Inc, Groton, CT, USA

Full list of author information is available at the end of the article
}

of pegaptanib sodium, significant reductions in central macular thickness and changes in visual acuity were reported in subjects with DME compared to baseline [7] and compared to laser alone [8]. Intravitreal pegaptanib also has been used to delay or abrogate the need for vitrectomy for recurrent and nonclearing vitreous hemorrhage in proliferative DR in a consecutive case series [9].

The diabetic population is at an increased risk of vascular complications, including myocardial infarction [10], stroke [11-14], coronary heart disease [14,15], and peripheral artery disease [16]. Although pegaptanib has an established long-term safety record in subjects with neovascular AMD $[17,18]$ the question arises as to whether or not the intraocular administration of antiVEGF agents in the diabetic population poses an additional systemic risk. Because there is a lack of large,

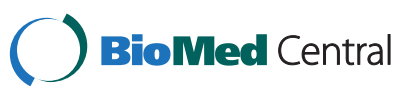


comparative studies examining the systemic effects of anti-VEGF therapies, understanding the implications of administering these agents in individuals with diabetes is important information for the clinician. This retrospective analysis was performed to evaluate the safety of pegaptanib in the subset of patients with diabetes who were receiving pegaptanib for AMD (data on file, Pfizer Inc) $[19,20]$.

\section{Methods}

This pooled retrospective analysis evaluated the occurrence of prespecified adverse events in subjects with or without diabetes mellitus (type 1 and type 2) who were treated with pegaptanib sodium injection (Macugen, Eyetech Inc) for AMD. All subjects who received study treatment with pegaptanib $0.3 \mathrm{mg}$ by intravitreal injection in the Phase II through Phase IV clinical trials by way of randomization assignment, crossover design, protocol amendment, or change in dose assignment were included in the analysis (Table 1). These studies were conducted in full conformance with the principles of the Declaration of Helsinki or with the laws of the country in which the research was conducted, whichever afforded the greater protection to the study participant. Institutional Review Board or Ethics Committee approval was obtained from each clinical center and signed informed consent was obtained from all study participants.
In studies where subjects received $0.3 \mathrm{mg}$ doses and/ or other doses (sham or pegaptanib $1 \mathrm{mg}$ or $3 \mathrm{mg}$ ), only the period when they received the $0.3 \mathrm{mg}$ dose was included for compiling data on treatment exposure, adverse events, concomitant medications and discontinuations. The treatment-exposure period was defined as the time from the first pegaptanib $0.3 \mathrm{mg}$ injection to 42 days after the last injection.

Standard summary tables filtered by the prespecified treatment-emergent adverse event MedDRA [Medical Dictionary for Regulatory Activities, version 12.1] preferred terms (PTs) (Table 2) were prepared. These included endophthalmitis, increased intraocular pressure (IOP), retinal injury, intraocular hemorrhage, traumatic cataract, hypersensitivity reactions, stroke, myocardial infarction, and other cardiovascular and cerebrovascular thromboembolic events $[21,22]$. The ocular and nonocular (hypersensitivity) terms were those used to identify the ocular and hypersensitivity risks for pegaptanib in the risk management plan and for which the sponsor conducts regular pharmacovigilance monitoring. The cardiovascular, cerebrovascular and peripheral vascular arterial thromboembolic events listed were selected based on Antiplatelet Trialists' Collaboration (APTC) criteria [21,22] and are the terms followed as part of routine pharmacovigilance by the sponsor. In order to detect whether the clinical database contained any of the prespecified treatment-emergent PTs, each PT was

Table 1 Clinical studies included in the analysis in which subjects received $0.3 \mathbf{m g}$ pegaptanib

\begin{tabular}{|c|c|c|c|c|c|c|}
\hline \multirow[t]{4}{*}{ Study } & \multirow{4}{*}{$\begin{array}{l}\text { Duration of } \\
\text { Treatment }\end{array}$} & \multirow[t]{4}{*}{ Treatment Groups } & \multirow{2}{*}{\multicolumn{3}{|c|}{$\begin{array}{c}\text { Pegaptanib sodium } 0.3 \mathrm{mg} \\
\text { Subjects }\end{array}$}} & \multirow[t]{4}{*}{ Reference } \\
\hline & & & & & & \\
\hline & & & \multirow{2}{*}{$\begin{array}{c}\text { With } \\
\text { Diabetes } \\
\mathrm{N}=165\end{array}$} & \multirow{2}{*}{$\begin{array}{l}\text { Without } \\
\text { Diabetes } \\
\mathrm{N}=1421\end{array}$} & \multirow{2}{*}{$\begin{array}{c}\begin{array}{c}\text { With } \\
\text { Diabetes }\end{array} \\
N=26\end{array}$} & \\
\hline & & & & & & \\
\hline NCT00321997 (EOP1003; randomized) & Up to 5 years & Pegaptanib 0.3, 1, 3 mg; sham & $22(13.3 \%)$ & $208(14.6 \%)$ & $7(26.9 \%)$ & {$[15]$} \\
\hline NCT00021736 (EOP1004; randomized) & Up to 5 years & Pegaptanib 0.3, 1, 3 mg; sham & $20(12.1 \%)$ & $182(12.8 \%)$ & $14(53.8 \%)$ & {$[17]$} \\
\hline NCT00215670 (EOP1006; randomized) & Up to 2 years & Pegaptanib 0.3, 1, 3 mg & $1(0.6 \%)$ & $41(2.9 \%)$ & $0(0 \%)$ & {$[29]$} \\
\hline NCT00087763 (EOP1009; randomized) & $\begin{array}{l}1 \text { year; with no } \\
\text { treatment } \\
\text { weeks } 12 \text { to } 24\end{array}$ & Pegaptanib 0.3, 1 mg; sham & $4(2.4 \%)$ & $60(4.2 \%)$ & $5(19.2 \%)$ & * \\
\hline NCT00088192 (EOP1010; open-label) & Up to 3 years & Pegaptanib 0.3 mg & $67(40.6 \%)$ & $370(26.0 \%)$ & $0(0 \%)$ & {$[30]$} \\
\hline NCT00134667** EOP1012; randomized) & Up to 2 years & $\begin{array}{c}\text { Pegaptanib } 0.3 \mathrm{mg} ; \\
\text { pegaptanib } 0.3 \mathrm{mg}+\text { PDT }\end{array}$ & $16(9.7 \%)$ & $149(10.5 \%)$ & $0(0 \%)$ & \\
\hline $\begin{array}{l}\text { NCT00150202/ NCT00239928 } \\
\quad \text { (A5751010/ A5751015; open-label) }\end{array}$ & Up to 4 years & Pegaptanib 0.3, $1 \mathrm{mg}$ & $7(4.2 \%)$ & $72(5.1 \%)$ & $0(0 \%)$ & {$[30]^{* * *}$} \\
\hline NCT00324116 (A5751016; open-label) & 1 year & Pegaptanib 0.3 mg & $11(6.7 \%)$ & $70(4.9 \%)$ & $0(0 \%)$ & $\dagger$ \\
\hline NCT00327470 (A5751017; open-label) & Up to 2 years & Pegaptanib 0.3 mg & $17(10.3 \%)$ & 269 (18.9\%) & $0(0 \%)$ & + \\
\hline
\end{tabular}

PDT: photodynamic therapy with verteporfin.

*Unpublished observation ([by author or pharma, year]).

**Unpublished results; trial terminated.

***Study A5751015 was an extension of study A5751010 and were considered as a single study for this manuscript.

'Unpublished observations (Estephan M, Troy S, Starita C, for the French Macugen in Early Onset CNV Study Group presented at European Society of Retina Specialists - 10th EURETINA Congress. Paris, France; 2010: Poster 1016). 
Table 2 Prespecified adverse event preferred terms, MedDRA version $\mathbf{1 2 . 1}$

\begin{tabular}{|c|c|}
\hline Ocular & Nonocular \\
\hline Endophthalmitis & Drug hypersensitivity \\
\hline Panophthalmitis & Hypersensitivity \\
\hline Intraocular pressure, increased & Hypersensitivity NOS (v. 5.1) \\
\hline Ocular hypertension & Anaphylactic shock \\
\hline Glaucoma & Anaphylactic reaction \\
\hline Glaucoma NOS (v. 5.1) & Anaphylactoid shock \\
\hline Glaucoma, traumatic & Anaphylactoid reaction \\
\hline Retinal injury & Angioedema \\
\hline Retinal tear & Angioneurotic edema (v. 5.1) \\
\hline Retinal detachment & Blepharitis, allergic \\
\hline Retinal hemorrhage & Dermatitis, contact \\
\hline Retinal toxicity & Dermatitis, allergic \\
\hline $\begin{array}{l}\text { Detachment of retinal } \\
\text { pigment epithelium }\end{array}$ & Toxic skin eruption \\
\hline Retinal pigment epitheliopathy (v. 5.1) & Toxic epidermal necrolysis \\
\hline Eye hemorrhage & Lyell syndrome (v. 5.1) \\
\hline Eye hemorrhage NOS (v. 5.1) & Drug eruption \\
\hline Vitreous hemorrhage & Dermatitis medicamentosa (v. 5.1) \\
\hline Cataract traumatic & Erythema \\
\hline Erythema multiforme & Urticaria \\
\hline Tongue edema & Stevens-Johnson syndrome \\
\hline Pharyngeal edema & Stevens-Johnson syndrome (v. 5.1) \\
\hline Laryngeal edema & Rash \\
\hline Latex allergy & Rash NOS (v. 5.1) \\
\hline Paresthesia oral & Skin reaction \\
\hline Paraesthesia mucosal & $\begin{array}{l}\text { Acute generalized } \\
\text { exanthematous pustulosis }\end{array}$ \\
\hline Paraesthesia mucosal NOS (v. 5.1) & $\begin{array}{l}\text { Drug rash with eosinophilia } \\
\text { and systemic symptoms }\end{array}$ \\
\hline \multicolumn{2}{|c|}{ Antiplatelet Trialists' Collaboration Events } \\
\hline Cardiovascular & Cerebrovascular \\
\hline Acute myocardial infarction & Brain stem infarction \\
\hline Cardiac arrest & Cerebrovascular accident \\
\hline Cardiac failure congestive & Lacunar infarction \\
\hline Myocardial infarction & Cerebral hemorrhage \\
\hline Retroperitoneal hemorrhage & Transient ischemic attack \\
\hline Sudden death & Peripheral vascular thrombosis \\
\hline Silent myocardial infarction & Pulmonary embolism \\
\hline Coronary artery stenosis & Deep vein thrombosis \\
\hline Acute coronary syndrome & Thrombosis \\
\hline Angina pectoris & Ischemia \\
\hline Angina unstable & Ischemia NOS (v. 5.1) \\
\hline
\end{tabular}

MedDRA: Medical Dictionary for Regulatory Activities.

NOS: not otherwise specified.

$\mathrm{V}$ : version. divided into a separate text string for extensive search purposes so that if a PT recorded in the clinical database contained any of the text strings, it was considered a match. Any unrelated terms were removed after the first-round review.

The frequency of prespecified treatment-emergent event terms as well as other safety data reported by the pooled AMD subjects with a medical history of diabetes mellitus were compared with the corresponding data reported by the pooled AMD subjects without a medical history of diabetes mellitus. Events were categorized by severity (mild, moderate, severe); in cases where the subject experienced the same event more than once, the worst severity was presented.

Because sham injections were administered to subjects with diabetes in 3 of the pooled studies, an additional analysis of APTC events reported in this population was conducted for comparison to pegaptanib-treated subjects in the primary analysis. Events occurring in subjects who received both pegaptanib and sham at different time points in the study were counted twice if the event was reported during each time period.

\section{Results}

\section{Subject disposition and demographics}

Nine sponsor-administered clinical studies, both randomized and open-label of 1 to 5 years' duration, in which subjects received pegaptanib $0.3 \mathrm{mg}$ were included in the analysis. These consisted of all completed Phase II through IV trials evaluating pegaptanib in AMD available at the time the plan for the pooled analysis was finalized. There were 1,586 subjects enrolled, including $165(10.4 \%)$ with diabetes and 1,421 (89.6\%) without diabetes, receiving pegaptanib $0.3 \mathrm{mg}$. The number of pegaptanib $0.3 \mathrm{mg}$ injections received by the subjects with and without diabetes was similar; the subjects with diabetes received a mean of 8.8 injections (range, 1-39) over a mean of 52.4 weeks and the subjects without diabetes received a mean of 9.7 injections (range, 1-44) over a mean of 57.5 weeks. The diabetic population had a higher percentage of males than the nondiabetic population $(51.5 \%$ vs. $42.6 \%)$ and a lower percentage of Caucasian/white subjects ( $44.2 \%$ vs. $61.3 \%$, respectively); this largely reflected a higher percentage of subjects with an "unspecified" race in the diabetic population $(47.9 \%$ vs. $31.6 \%$, respectively). The mean age was similar between groups (75.3 [range, 56-89] and 75.9 [range, 40-94] years for the subjects with and without diabetes, respectively).

\section{Medical history}

As expected, the group with diabetes had a greater proportion of subjects with a medical history of metabolic and vascular system disorders, including vascular 
hypertension, coronary artery disorders, and lipid disorders/analyses; only cardiac arrhythmias and thyroid gland disorders occurred more frequently in subjects without diabetes. Most of the subjects with diabetes (73.3\%) and subjects without diabetes (66.1\%) reported a history of at least 1 ocular disease in the study eye, with glaucoma and ocular hypertension occurring more frequently in the subjects with diabetes than in those without diabetes ( $11.5 \%$ vs. $7.9 \%$, respectively). Subjects with diabetes also had more eye therapeutic procedures than those without diabetes ( $21.8 \%$ vs. $12.0 \%$, respectively).

\section{Early discontinuations from treatment}

In all, $72(43.6 \%)$ subjects in the diabetic group and 485 (34.8\%) subjects in the nondiabetic group discontinued treatment prematurely; causes and their reporting rates were similar between groups. The majority of discontinuations in the diabetic and nondiabetic groups were due to lack of availability of the study drug (31 [18.8\%] and 167 [11.8\%], respectively) and investigator or sponsor decision (22 [13.3\%] and 171 [12\%]). There were no deaths leading to early discontinuation in the diabetic group versus $11(0.8 \%)$ in the nondiabetic group. Two (1.2\%) subjects in the diabetic group and $16(1.1 \%)$ subjects in the nondiabetic group discontinued due to adverse events.

Adverse events leading to early discontinuation in the diabetic group included 1 subject each with pneumonia not otherwise specified (NOS)/myocardial infarction (unrelated to study drug), and retinal hemorrhage/ cerebrovascular accident (causality not specified); both events were fatal. In the nondiabetic group, ocular adverse events leading to discontinuation were macular degeneration including choroidal neovascularization (1 subject), retinal detachment (2 subjects), and visual acuity reduced (3 subjects). Three adverse events resulted in death and early discontinuation: metastatic cancer in 2 subjects and aortic aneurysm rupture in 1 subject; none were related to the study drug. There were no notable differences between the groups in events frequently associated with diabetes; the subjects with diabetes reported 1 occurrence each of myocardial infarction, retinal hemorrhage, and cerebrovascular accident and the subjects without diabetes reported 1 occurrence each of retinal tear and retinal hemorrhage, and 2 occurrences of retinal detachment.

\section{Treatment-emergent adverse events}

Treatment-emergent adverse events (by System Organ Class and PT) were reported by 117 (70.9\%) and 1,095 (77.1\%) of subjects in the diabetic and nondiabetic groups, respectively, who received pegaptanib. The most common treatment-emergent adverse events were eye disorders, with similar reporting rates in both diabetic and nondiabetic groups (65.5\% vs. $66.6 \%$, respectively). In order from highest to lowest, eye pain, reduced visual acuity, punctate keratitis, and vitreous floaters were the most frequent occurrences (reported in $15 \%$ to $22 \%$ of subjects).

In general, there were no notable differences between groups with respect to treatment-emergent, nonocular adverse events. Among the nonocular adverse events, arthralgia ( $3.6 \%$ vs. $2.4 \%)$, chest pain $(2.4 \%$ vs. $1.2 \%)$, dizziness $(4.2 \%$ vs. $1.4 \%)$, aggravated hypertension $(3.0 \%$ vs. $1.5 \%)$, nausea (3.0\% vs. $1.8 \%)$, and vomiting NOS $(4.2 \%$ vs. $0.8 \%$ ) were more frequently reported in subjects with diabetes compared with subjects without diabetes, respectively. Nasopharyngitis was more frequent in subjects without diabetes (4.0\%) compared with subjects with diabetes (2.4\%).

\section{Prespecified ocular and hypersensitivity adverse events}

In all, $28(17.0 \%)$ subjects in the diabetic group reported 50 prespecified ocular adverse events and $294(20.7 \%)$ in the nondiabetic group reported 601 prespecified events regardless of causality. The incidence and severity of prespecified ocular adverse events (study eye) are shown in Table 3. There were no differences between groups in the incidence or severity of endophthalmitis, retinal detachment, retinal hemorrhage, retinal tear, and vitreous hemorrhage. Retinal pigment epitheliopathy was reported more frequently in subjects with diabetes, and IOP elevations were reported more frequently in the subjects without diabetes. For injection- or therapyrelated ocular adverse events, no difference in the incidence or severity of any event was found; 23 injectionrelated events were reported by $15(9.1 \%)$ subjects with diabetes and 368 events were reported by 164 (11.5\%) subjects without diabetes. In all, 9 prespecified ocular events related to study therapy were reported by 4 (2.4\%) subjects with diabetes and 57 events were reported by $43(3.0 \%)$ subjects without diabetes. Rash NOS was the only prespecified nonocular (hypersensitivity) adverse event that occurred in both subjects with and without diabetes $(1.2 \%$ vs. $0.8 \%$, respectively). All other hypersensitivity events were reported in subjects without diabetes (Table 4).

\section{Thromboembolic adverse events}

Prespecified APTC adverse events irrespective of causality were reported in $10(6.1 \%)$ subjects with diabetes and in 60 (4.2\%) subjects without diabetes. Serious APTC events were reported by $6.1 \%$ and $3.4 \%$ of subjects with and without diabetes, respectively, and severe APTC events were reported by $3.6 \%$ and $2.4 \%$, respectively. Cerebrovascular accident was reported more frequently in the subjects with diabetes than those without diabetes $(1.8 \%$ vs. $0.6 \%$, respectively), while coronary artery atherosclerosis was 
Table 3 Incidence and severity of prespecified ocular adverse events in the study eye, all causality

\begin{tabular}{|c|c|c|c|c|c|c|}
\hline \multirow{4}{*}{$\begin{array}{l}\text { Subjects } \\
\text { Preferred Term }\end{array}$} & \multicolumn{6}{|c|}{ Pegaptanib $0.3 \mathrm{mg}$} \\
\hline & \multirow{2}{*}{\multicolumn{3}{|c|}{$\begin{array}{c}\text { With Diabetes } \\
(\mathrm{N}=165)\end{array}$}} & \multirow{2}{*}{\multicolumn{3}{|c|}{$\begin{array}{c}\text { Without Diabetes } \\
(N=1,421)\end{array}$}} \\
\hline & & & & & & \\
\hline & $\mathrm{n}$ & $(\%)$ & Severe & $\mathrm{n}$ & (\%) & Severe \\
\hline Cataract, traumatic & 0 & 0 & 0 & 1 & $(0.1)$ & 0 \\
\hline $\begin{array}{l}\text { Detachment of retinal } \\
\text { pigment epithelium }\end{array}$ & 0 & 0 & 0 & 3 & $(0.2)$ & 0 \\
\hline Endophthalmitis & 1 & $(0.6)$ & 1 & 16 & $(1.1)$ & 14 \\
\hline Eye hemorrhage & 0 & 0 & 0 & 6 & $(0.4)$ & 2 \\
\hline Eye hemorrhage NOS & 0 & 0 & 0 & 3 & $(0.2)$ & 0 \\
\hline Glaucoma & 0 & 0 & 0 & 2 & $(0.1)$ & 0 \\
\hline Glaucoma NOS & 0 & 0 & 0 & 2 & $(0.1)$ & 0 \\
\hline $\begin{array}{l}\text { Intraocular pressure } \\
\text { increased }\end{array}$ & 13 & (7.9) & 0 & 155 & (10.9) & 6 \\
\hline Ocular hypertension & 0 & 0 & 0 & 11 & $(0.8)$ & 0 \\
\hline Retinal detachment & 1 & $(0.6)$ & 0 & 9 & $(0.6)$ & 5 \\
\hline Retinal hemorrhage & 8 & $(4.8)$ & 1 & 64 & $(4.5)$ & 6 \\
\hline $\begin{array}{l}\text { Retinal pigment } \\
\text { epitheliopathy }\end{array}$ & 4 & $(2.4)$ & 0 & 10 & $(0.7)$ & 0 \\
\hline Retinal tear & 1 & $(0.6)$ & 0 & 0 & $(0.4)$ & 0 \\
\hline Vitreous hemorrhage & 3 & $(1.8)$ & 0 & 21 & $(1.5)$ & 2 \\
\hline
\end{tabular}

'Preferred terms are from MedDRA [Medical Dictionary for Regulatory Activities, version 12.1]

NOS: not otherwise specified.

only reported in the subjects with diabetes (1.2\%; Table 5$)$. No life-threatening events occurred in the subjects with diabetes while $11(0.7 \%)$ were reported in the subjects without diabetes receiving pegaptanib. However, it was noted previously that 2 subjects with diabetes discontinued treatment early: 1 due to myocardial infarction and the other to a cerebrovascular accident; both had fatal outcomes. No prespecified, injection-related APTC adverse events were reported in either group. Cerebrovascular accident, the only study therapy related APTC event, was reported in $1(0.6 \%)$ subject with diabetes and $3(0.2 \%)$ subjects without diabetes.

The analysis identified 26 subjects with diabetes who received sham injection in the 3 controlled studies; baseline demographics were similar to those in the pegaptanib-treated group with diabetes. One APTC event was reported in 3 (11.5\%) sham-treated subjects: a life-threatening acute myocardial infarction; moderate severity angina pectoris; severe congestive cardiac failure (Table 5). No events led to death but 1 subject discontinued therapy.

\section{Deaths}

In total, $6(3.6 \%)$ subjects with diabetes and $28(2.0 \%)$ subjects without diabetes died during the studies. Death was considered unrelated to treatment with pegaptanib
Table 4 Incidence and severity of hypersensitivity adverse events, all causality

\begin{tabular}{|c|c|c|c|c|c|c|c|c|}
\hline \multirow{4}{*}{$\begin{array}{l}\text { Number } \\
\text { of Subjects } \\
\text { Preferred Term }\end{array}$} & \multicolumn{8}{|c|}{ Pegaptanib $0.3 \mathrm{mg}$} \\
\hline & \multirow{2}{*}{\multicolumn{4}{|c|}{$\begin{array}{c}\text { With Diabetes } \\
(\mathrm{N}=165)\end{array}$}} & \multirow{2}{*}{\multicolumn{4}{|c|}{$\begin{array}{c}\text { Without Diabetes } \\
(N=1421)\end{array}$}} \\
\hline & & & & & & & & \\
\hline & n & $(\%)$ & Severe & LT & n & $(\%)$ & Severe & LT \\
\hline Blepharitis, allergic & 0 & 0 & 0 & 0 & 1 & $(0.1)$ & 0 & 0 \\
\hline Dermatitis, allergic & 0 & 0 & 0 & 0 & 1 & $(0.1)$ & 0 & 0 \\
\hline Dermatitis, contact & 0 & 0 & 0 & 0 & 7 & $(0.5)$ & 0 & 0 \\
\hline Drug hypersensitivity & 0 & 0 & 0 & 0 & 6 & $(0.4)$ & 0 & 0 \\
\hline Erythema & 0 & 0 & 0 & 0 & 2 & $(0.1)$ & 0 & 0 \\
\hline Hypersensitivity & 0 & 0 & 0 & 0 & 2 & $(0.1)$ & 0 & 0 \\
\hline Hypersensitivity NOS & 0 & 0 & 0 & 0 & 5 & $(0.4)$ & 0 & 0 \\
\hline Rash & 0 & 0 & 0 & 0 & 2 & $(0.1)$ & 0 & 0 \\
\hline Rash NOS & 2 & $(1.2)$ & 0 & 0 & 12 & $(0.8)$ & 0 & 0 \\
\hline Toxic skin eruption & 0 & 0 & 0 & 0 & 1 & $(0.1)$ & 0 & 0 \\
\hline Urticaria & 0 & 0 & 0 & 0 & 1 & $(0.1)$ & 0 & 0 \\
\hline
\end{tabular}

${ }^{1}$ Preferred terms are from MedDRA [Medical Dictionary for Regulatory Activities, version 12.1].

LT: life-threatening.

NOS: not otherwise specified.

in 33 cases; in 1 case death due to a ruptured abdominal aortic aneurysm was considered treatment-related. The most common causes of death were attributed to cardiovascular, cerebrovascular or peripheral vascular thrombotic events. Deaths reported in the subjects with diabetes included 1 occurrence of cerebrovascular accident deemed unknown in relationship to study drug administration. Deaths attributed to vascular events in the nondiabetic population included pulmonary embolism $(n=3)$, myocardial infarction $(n=2)$, cerebrovascular accident $(n=1)$, congestive heart failure $(n=2)$, cardiac/ cardiopulmonary arrest $(\mathrm{n}=2)$, ischemic heart disease $(\mathrm{n}=2)$, cardiomyopathy $(\mathrm{n}=1)$, and ruptured abdominal aortic aneurysm $(n=2)$. The remainder of the deaths were due to polytraumatism, respiratory failure/chronic cardiopulmonary disease, gastric cancer and metastatic colon and prostate cancers, brain metastasis, hypotension, Clostridium difficile colitis, chronic obstructive pulmonary disease, bronchopneumonia, and infection complicated by cardiac and renal failure.

\section{Discussion}

In this retrospective examination of pooled adverse events from AMD studies, subjects with diabetes, although more susceptible to disease-related ocular and thromboembolic events, had no increased risk as a result of pegaptanib $0.3 \mathrm{mg}$ therapy compared with those without diabetes. Since only $10 \%$ of all subjects had diabetes, comparisons between them and those without diabetes were, at best, unbalanced. Given this limitation, we 
Table 5 Incidence and severity of prespecified antiplatelet trialists' collaboration events, all causality ${ }^{1}$

\begin{tabular}{|c|c|c|c|c|c|c|c|c|c|c|c|c|}
\hline \multirow{4}{*}{$\begin{array}{l}\text { Number of Subjects } \\
\text { Preferred Term }{ }^{2}\end{array}$} & \multicolumn{8}{|c|}{ Pegaptanib sodium $0.3 \mathrm{mg}$} & \multirow{3}{*}{\multicolumn{4}{|c|}{$\begin{array}{c}\text { Sham } \\
\text { With Diabetes } \\
(N=26)\end{array}$}} \\
\hline & \multirow{2}{*}{\multicolumn{4}{|c|}{$\begin{array}{c}\text { With Diabetes } \\
(N=165)\end{array}$}} & \multirow{2}{*}{\multicolumn{4}{|c|}{$\begin{array}{c}\text { Without Diabetes } \\
(\mathrm{N}=1421)\end{array}$}} & & & & \\
\hline & & & & & & & & & & & & \\
\hline & $\mathrm{n}$ & (\%) & Sev & LT & $\mathrm{n}$ & (\%) & Sev & LT & $\mathrm{n}$ & (\%) & Sev & $\mathrm{Lt}$ \\
\hline Acute myocardial infarction & 0 & 0 & 0 & 0 & 1 & $(0.1)$ & 0 & 0 & 1 & (3.8) & 0 & 1 \\
\hline Angina pectoris & 1 & $(0.6)$ & 1 & 0 & 8 & $(0.6)$ & 2 & 1 & 1 & (3.8) & 0 & 0 \\
\hline Angina unstable & 0 & 0 & 0 & 0 & 4 & $(0.3)$ & 2 & 0 & 0 & 0 & 0 & 0 \\
\hline Cardiac arrest & 0 & 0 & 0 & 0 & 2 & $(0.1)$ & 0 & 2 & 0 & 0 & 0 & 0 \\
\hline Cardiac failure congestive & 0 & 0 & 0 & 0 & 5 & $(0.4)$ & 1 & 2 & 1 & (3.8) & 1 & 0 \\
\hline Cerebral hemorrhage & 0 & 0 & 0 & 0 & 1 & $(0.1)$ & 0 & 1 & 0 & 0 & 0 & 0 \\
\hline Cerebrovascular accident & 3 & $(1.8)$ & 3 & 0 & 9 & $(0.6)$ & 5 & 1 & 0 & 0 & 0 & 0 \\
\hline Coronary artery atherosclerosis & 2 & $(1.2)$ & 1 & 0 & 0 & 0 & 0 & 0 & 0 & 0 & 0 & 0 \\
\hline Coronary artery disease NOS & 1 & $(0.6)$ & 0 & 0 & 9 & $(0.6)$ & 3 & 0 & 0 & 0 & 0 & 0 \\
\hline Coronary artery occlusion & 0 & 0 & 0 & 0 & 1 & $(0.1)$ & 1 & 0 & 0 & 0 & 0 & 0 \\
\hline Myocardial infarction & 2 & $(1.2)$ & 1 & 0 & 10 & $(0.7)$ & 7 & 2 & 0 & 0 & 0 & 0 \\
\hline Pulmonary embolism & 1 & $(0.6)$ & 1 & 0 & 7 & $(0.5)$ & 4 & 1 & 0 & 0 & 0 & 0 \\
\hline Retroperitoneal hemorrhage & 0 & 0 & 0 & 0 & 1 & $(0.1)$ & 1 & 0 & 1 & $(0.1)$ & 1 & 0 \\
\hline Thrombosis & 1 & $(0.6)$ & 1 & 0 & 0 & 0 & 0 & 0 & 0 & 0 & 0 & 0 \\
\hline Transient ischemic attack & 1 & $(0.6)$ & 0 & 0 & 8 & $(0.6)$ & 2 & 0 & 0 & 0 & 0 & 0 \\
\hline Silent myocardial infarction & 1 & $(0.6)$ & 0 & 0 & 0 & 0 & 0 & 0 & 0 & 0 & 0 & 0 \\
\hline Ischemia NOS & 0 & 0 & 0 & 0 & 1 & $(0.1)$ & 0 & 0 & 0 & 0 & 0 & 0 \\
\hline Deep vein thrombosis & 0 & 0 & 0 & 0 & 4 & $(0.3)$ & 1 & 0 & 0 & 0 & 0 & 0 \\
\hline
\end{tabular}

${ }^{1}$ In cases in which subjects experienced the same event more than once, the worst severity was presented.

${ }^{2}$ Adverse event with a start date between the day of the first injection and at most 42 days after the last injection.

Preferred terms are from MedDRA [Medical Dictionary for Regulatory Activities, version 12.1].

LT: life-threatening.

NOS: not otherwise specified.

Sev: severe.

found no notable differences between the subjects with and without diabetes in the frequencies of events in general or in particular events related to diabetes that were reported. Differences identified between the groups involving adverse events that occurred more often in subjects with diabetes were either expected or were not considered important. The proportions of subjects with diabetes reporting prespecified ocular adverse events were similar to or less than the corresponding proportions reported in the nondiabetic population. The reporting rate and incidence of the prespecified nonocular events (hypersensitivity reactions) were similar between the 2 groups.

The proportions of subjects with diabetes with prespecified APTC adverse events were considered similar to the proportions of those without diabetes with APTC events. However, differences in individual arterial thromboembolic adverse event terms between the 2 populations were identified. Cerebrovascular accident and myocardial infarction were reported with a slightly higher frequency in the subjects with diabetes. There were also 3 events only reported by the diabetic population: coronary artery atherosclerosis, thrombosis, and silent myocardial infarction. In addition, a comparison of nonocular medical histories between the populations indicated that metabolic, vascular, and cardiac disorders were reported more often in the subjects with diabetes, and these disorders were consistent with those generally experienced by a population with a history of diabetes. Based on the deaths reported, there did not appear to be any increased risk of death to subjects with diabetes mellitus as a result of pegaptanib treatment.

Although involving only a small population of people with diabetes receiving sham treatment, these results were further confirmed in the pooled analysis of the 3 studies in which subjects with diabetes were treated with sham injections. Overall, there was no difference in the occurrence of APTC events between subjects with diabetes receiving sham injections and those receiving pegaptanib in the pooled analysis of 9 studies.

As the known properties of VEGF include angiogenesis, increased vascular permeability, and maintenance of vascular endothelial integrity, there are a number of theoretical risks that may be associated with systemic 
anti-VEGF activity [4]. The systemic administration of high dose bevacizumab in early clinical trials in oncology was associated with potential complications of hypertension, proteinuria, impaired wound healing, gastrointestinal perforation, hemorrhage and thrombosis [23]. The systemic VEGF inhibition effects with pegaptanib are not expected due to VEGF $_{165}$ selectivity and low systemic concentrations following intravitreal administration. In the present study, although the frequency of APTCs was low in both groups, subjects with diabetes appeared to be at an elevated risk of certain APTC adverse events compared to those without diabetes. Thus, the potential for systemic effects following treatment for AMD may be of greater concern in this population. In a 3-year safety study of pegaptanib, there were no thromboembolic cardiovascular accidents or nonocular hemorrhagic events following continuous treatment [18] while in a pooled analysis of data from the ranibizumab trials there was a significantly increased risk of cardiovascular accidents [24] and nonocular hemorrhages [25] in the treated group compared to sham. Bevacizumab has been used increasingly off-label for treatment of AMD [23]; the risk of these side effects following intravitreal injection are not known due to the lack of systematic reporting [25-27]. Of note, in a study of individuals with type 2 diabetes undergoing vitrectomy following intravitreal injection of bevacizumab, mean plasma VEGF concentrations were reduced approximately 10-fold (from 92.0 to $9.7 \mathrm{pg} / \mathrm{ml}$ ) 1 day after injection, clearly demonstrating entry into the systemic circulation [28].

This retrospective examination of pooled adverse events from AMD studies has certain strengths and limitations. Its strengths include the large multinational population from which the analysis is derived and the rigorous study conduct and monitoring of adverse events in these populations. As noted above, however, the difference in size between the group with diabetes and the group without did not provide a balanced comparison in terms of numbers. Other limitations include combining study protocols that were of differing designs and lengths and pooling clinical studies that were conducted over a period of many years.

\section{Conclusions}

Given consideration of the limitations of the analysis, pegaptanib sodium exposure does not appear to result in an increased risk for arterial thromboembolic or other adverse systemic effects above what would be observed in a sham-treated AMD population with cormorbid diabetes. There does not appear to be an incremental increase in the risk of APTC events in AMD subjects with diabetes due to treatment with pegaptanib.

\section{Competing interests}

All authors are currently and were employees of Pfizer Inc at the time of study conduct and development of the manuscript.

\section{Authors' contributions}

TD, KK, MS conceived of the work that led to the assembly and review of the acquired data, and the interpretation and submission of the results. TD and MS drafted and revised the manuscript and KK provided a critical review of the content. All authors approved the manuscript for submission.

\section{Funding}

This study was sponsored by Pfizer Inc.

\section{Acknowledgements}

The authors wish to acknowledge Robert L. Wiseman for his contributions to the organization of the study findings. Editorial support, including contributing to the first draft of the paper, revising the paper based on author comments, and styling the paper for journal submission, was provided by Linda Whetter, PhD, DVM, of Zola Associates and was funded by Pfizer Inc. Additional editorial support to address reviewers' comments and associated revisions were provided by Mukund Nori, PhD, MBA, CMPP, of UBC Envision Group and was funded by Pfizer Inc.

\section{Author details}

'Pfizer Inc, Groton, CT, USA. ${ }^{2}$ Pfizer Inc, New York, NY, USA. ${ }^{3}$ The New York Eye and Ear Infirmary, New York, NY, USA.

Received: 14 December 2011 Accepted: 12 July 2012

Published: 8 August 2012

\section{References}

1. Adamis AP, Berman AJ: Immunological mechanisms in the pathogenesis of diabetic retinopathy. Semin Immunopathol 2008, 30(2):65-84.

2. Gardner TW, Antonetti DA: Novel potential mechanisms for diabetic macular edema: leveraging new investigational approaches. Curr Diab Rep 2008, 8(4):263-269.

3. Kern TS: Contributions of inflammatory processes to the development of the early stages of diabetic retinopathy. Exp Diabetes Res 2007, 2007:95103.

4. Wirostko B, Wong TY, Simo R: Vascular endothelial growth factor and diabetic complications. Prog Retin Eye Res 2008, 27(6):608-621.

5. Karim R, Tang B: Use of antivascular endothelial growth factor for diabetic macular edema. Clin Ophthalmol 2010, 4:493-517.

6. Nicholson BP, Schachat AP: A review of clinical trials of anti-VEGF agents for diabetic retinopathy. Graefes Arch Clin Exp Ophthalmol 2010, 248(7): 915-930.

7. Querques G, Bux AV, Martinelli D, laculli C, Noci ND: Intravitreal pegaptanib sodium (Macugen) for diabetic macular oedema. Acta Ophthalmol 2009, 87(6):623-630.

8. Querques G, Bux AV, Fusco AR, laculli C, Delle Noci N: Pegaptanib Sodium versus Pegaptanib Sodium Combined with Macular Laser Photocoagulation or Laser Alone for Diabetic Macular Edema. J Ophthalmol 2009, 2009:672178.

9. Hornan D, Edmeades N, Krishnan R, Khan J, Lochhead J: Use of pegaptanib for recurrent and non-clearing vitreous haemorrhage in proliferative diabetic retinopathy. Eye (Lond) 2010, 24(8):1315-1319.

10. Schramm TK, Gislason GH, Kober L, Rasmussen S, Rasmussen JN, Abildstrom SZ, Hansen ML, Folke F, Buch P, Madsen M, et al: Diabetes patients requiring glucose-lowering therapy and nondiabetics with a prior myocardial infarction carry the same cardiovascular risk: a population study of 3.3 million people. Circulation 2008, 117(15):1945-1954.

11. Giorda CB, Avogaro A, Maggini M, Lombardo F, Mannucci E, Turco S, Alegiani SS, Raschetti R, Velussi M, Ferrannini E: Incidence and risk factors for stroke in type 2 diabetic patients: the DAl study. Stroke 2007, 38(4):1154-1160.

12. Hyvarinen M, Tuomilehto J, Laatikainen T, Soderberg S, Eliasson M, Nilsson P, Qiao Q: The impact of diabetes on coronary heart disease differs from that on ischaemic stroke with regard to the gender. Cardiovasc Diabetol 2009, 8:17.

13. Jeerakathil T, Johnson JA, Simpson SH, Majumdar SR: Short-term risk for stroke is doubled in persons with newly treated type 2 diabetes 
compared with persons without diabetes: a population-based cohort study. Stroke 2007, 38(6):1739-1743.

14. Sarwar N, Gao P, Seshasai SR, Gobin R, Kaptoge S, Di Angelantonio E, Ingelsson E, Lawlor DA, Selvin E, Stampfer M, et al: Diabetes mellitus, fasting blood glucose concentration, and risk of vascular disease: a collaborative meta-analysis of 102 prospective studies. Lancet 2010, 375(9733):2215-2222.

15. Haffner SM, Lehto S, Ronnemaa T, Pyorala K, Laakso M: Mortality from coronary heart disease in subjects with type 2 diabetes and in nondiabetic subjects with and without prior myocardial infarction. N Engl J Med 1998, 339(4):229-234.

16. Peripheral arterial disease in people with diabetes. Diabetes Care 2003, 26(12):3333-3341.

17. D'Amico DJ, Masonson HN, Patel M, Adamis AP, Cunningham ET Jr, Guyer DR, Katz B: Pegaptanib sodium for neovascular age-related macular degeneration: two-year safety results of the two prospective, multicenter, controlled clinical trials. Ophthalmology 2006, 113(6):992-1001. e1006.

18. Singerman $L$, Masonson $H$, Patel $M$, Adamis AP, Buggage $R$, Cunningham $E$, Goldbaum M, Katz B, Guyer D: Pegaptanib sodium for neovascular age-related macular degeneration: third-year safety results of the VEGF Inhibition Study in Ocular Neovascularisation (VISION) trial. Br J Ophthalmol 2008, 92(12):1606-1611.

19. Apte RS: Pegaptanib sodium for the treatment of age-related macular degeneration. Expert Opin Pharmacother 2008, 9(3):499-508.

20. Gragoudas ES, Adamis AP, Cunningham ET Jr, Feinsod M, Guyer DR: Pegaptanib for neovascular age-related macular degeneration. N Engl J Med 2004, 351(27):2805-2816.

21. Secondary prevention of vascular disease by prolonged antiplatelet treatment. Antiplatelet Trialists' Collaboration. Br Med J (Clin Res Ed) 1988 296(6618):320-331.

22. Collaborative overview of randomised trials of antiplatelet therapy-l: Prevention of death, myocardial infarction, and stroke by prolonged antiplatelet therapy in various categories of patients. Antiplatelet Trialists' Collaboration. BMJ 1994, 308(6921):81-106.

23. Kamba T, McDonald DM: Mechanisms of adverse effects of anti-VEGF therapy for cancer. Br J Cancer 2007, 96(12):1788-1795.

24. Ueta T, Yanagi Y, Tamaki Y, Yamaguchi T: Cerebrovascular accidents in ranibizumab. Ophthalmology 2009, 116(2):362

25. Schmucker C, Loke YK, Ehlken C, Agostini HT, Hansen LL, Antes G, Lelgemann M: Intravitreal bevacizumab (Avastin) versus ranibizumab (Lucentis) for the treatment of age-related macular degeneration: a safety review. Br J Ophthalmol 2011, 95(3):308-317.

26. Micieli JA, Micieli A, Smith AF: Identifying systemic safety signals following intravitreal bevacizumab: systematic review of the literature and the Canadian Adverse Drug Reaction Database. Can J Ophthalmol 2010, 45(3):231-238.

27. Schmucker C, Ehlken C, Hansen LL, Antes G, Agostini HT, Lelgemann M: Intravitreal bevacizumab (Avastin) vs. ranibizumab (Lucentis) for the treatment of age-related macular degeneration: a systematic review. Curr Opin Ophthalmol 2010, 21(3):218-226.

28. Matsuyama K, Ogata N, Matsuoka M, Wada M, Takahashi K, Nishimura T: Plasma levels of vascular endothelial growth factor and pigment epithelium-derived factor before and after intravitreal injection of bevacizumab. Br J Ophthalmol 2010, 94(9):1215-1218.

29. Apte RS, Modi M, Masonson H, Patel M, Whitfield L, Adamis AP: Pegaptanib 1-year systemic safety results from a safety-pharmacokinetic trial in patients with neovascular age-related macular degeneration. Ophthalmology 2007, 114(9):1702-1712.

30. Ishibashi T: Long Term Efficacy and Safety Profile of Pegaptanib Sodium for Age-related Macular Degeneration with Choroidal Neovascularization - Evaluation of Extended Phase II Clinical Trial. Nippon Ganka Gakkai Zasshi 2011, 115(2):122-133.

\section{doi:10.1186/1471-2415-12-37}

Cite this article as: Dombi et al:: A retrospective, pooled data analysis of the safety of pegaptanib sodium in the treatment of age-related macular degeneration in subjects with or without diabetes mellitus. BMC Ophthalmology 2012 12:37.

\section{Submit your next manuscript to BioMed Central and take full advantage of:}

- Convenient online submission

- Thorough peer review

- No space constraints or color figure charges

- Immediate publication on acceptance

- Inclusion in PubMed, CAS, Scopus and Google Scholar

- Research which is freely available for redistribution 